\title{
Lacrimal Apparatus
}

National Cancer Institute

\section{Source}

National Cancer Institute. Lacrimal Apparatus. NCI Thesaurus. Code C32905.

The organs associated with the production and removal of tears including the secretory glands, drainage system, and nerves. 